\title{
Characterising and developing vocational mathematical knowledge
}

\author{
A. Bakker
}

Published online: 28 April 2014

(C) The Author(s) 2014. This article is published with open access at Springerlink.com

\begin{abstract}
In this introductory article, I argue why this special issue focuses on the question of how the mathematical knowledge required at work can be characterised and developed in vocational education and workplace training. After some words on the importance of this subfield of mathematics education and the need to rethink metaphors of learning in this area, I summarise the structure of the special issue and highlight a few main points raised in the various contributions.
\end{abstract}

Keywords Boundary crossing · Metaphors of learning · Transition · Webbing - Webs of reasons · Workplace mathematics

It seems impossible to analyze education - in schooling, craft apprenticeship, or any other form - without considering its relations with the world for which it ostensibly prepares people. (Lave, 1988, p. xiii)

This opening sentence of Lave's (1988) seminal book on cognition in practice underlines the importance of studying relations between knowledge taught in education, on the one hand, and knowledge used in daily life or workplace settings, on the other. Though she writes "it seems impossible to analyze education... without considering" such relations, studying these relations and strengthening them prove to be hard. The vast majority of studies in mathematics education deal with students and their teachers in general education as a relatively closed system, and a small minority of studies deal with workplace mathematics with little consideration of its relation to school mathematics. Much less is known about transitional settings such as vocational education where students develop mathematical knowledge required in occupations or professions and learn to use it in practice. In this special issue, we bring together the latest insights in this area.

What we know from earlier research is mostly presented as a stark contrast between school mathematics and "street mathematics" (Nunes, Schliemann, \& Carraher, 1993). This research (including Lave's) has led to a fundamental critique of framing transitions of knowledge

\footnotetext{
A. Bakker $(\bowtie)$

Freudenthal Institute for Science and Mathematics Education, Utrecht University, Princetonplein 5, 3584

CC Utrecht, The Netherlands

e-mail: a.bakker4@uu.nl
} 
learned at school to knowledge applied in daily life or at work as a matter of transfer. It has also contributed to the development of situated approaches (Brown, Collins, \& Duguid, 1989; Greeno, 1998) and sociocultural theories (e.g., Lave \& Wenger, 1991). It became clear, as Tuomi-Gröhn and Engeström (2003) argued, that more sophisticated conceptions of transfer are required when we want to understand the boundary crossing between school and real-life settings such as work.

This special issue focuses on vocational education and workplace training, which could be seen as a transitional stage between cognition in captivity and cognition in the wild (Hutchins, 1995). In this domain of vocational education and workplace training, the nature of mathematics as generally applicable and abstract is confronted with practical constraints and concerns in concrete situations. Noss and Hoyles (1996) introduced the term situated abstraction to highlight the necessity of bridging these two aspects. How this should be done, however, remains an open question that has only received partial answers from small-scale intervention studies in vocational education (e.g., Bessot \& Ridgway, 2000; Hahn, 2000) and training in workplaces (e.g., Bakker, Kent, Hoyles, \& Noss, 2011; Hoyles, Bakker, Kent, \& Noss, 2007; Noss, Pozzi, \& Hoyles, 1999). Yet, there is interest in the interface between education and industry (Damlamian, Rodrigues, \& Sträßer, 2013).

The contributions in this special issue therefore focus on the question of how the mathematical knowledge required at work can be characterised and developed in vocational education and workplace training. We take vocational education to include post-compulsory mathematics and statistics education within programmes intended to prepare learners for specific careers or further develop existing workers, whether they are enrolled in specialised colleges or institutions or in mainstream universities. Most authors share an interest in activity theory (Roth \& Lee, 2007), boundary crossing (Akkerman \& Bakker, 2011, 2012) and the influence of technology on the visibility of mathematics at work (Hoyles, Noss, Kent, \& Bakker, 2010; Williams \& Wake, 2007).

The area of vocational education and workplace training has been chronically underrepresented in mathematics education research. One explanation may be that vocational education takes many different forms and positions in different countries. In some countries, vocational training is not part of the formal education system, whereas in other countries it is. In the Netherlands, more than half of the students in secondary education take a vocational route. In Germany, a little more than one third of the students aged $16+$ attend vocational schools, and in some countries, vocational education hardly exists. Internationally, vocational mathematics hardly exists as a taught subject (Sträßer, 2014). A second explanation is that the mathematics in professions is not always recognised as being mathematics (FitzSimons, 2002). A third reason for the lack of research may be that academics are typically unfamiliar with vocational education. Research in this area further requires hybrid expertise: not only of teaching and learning, but also of the sector of work for which students and apprentices are prepared. Collecting data at the boundaries of schools, college and workplaces can be challenging for reasons of permission and logistics. Last, we mention the lack of interest from policy makers and the lack of funding for research in vocational mathematics education, although there are some exceptions (see the Commentary by FitzSimons in this issue).

Yet, much can be learned from studies in vocational education, contributing knowledge with wider relevance to mathematics education. For example, research in this area can help us understand how to bridge the gap between abstract and general mathematics typically taught at schools, on the one hand, and situated workplace mathematics as typically found in workplaces on the other. This seems necessary for all those students who want to see the point of learning mathematics. "Why am I learning this?" is a common question in mathematics classrooms. 
Clarifying how mathematics or statistics is used in practice can help students see the point of learning it, also in general education (cf. Dierdorp, Bakker, Eijkelhof, \& van Maanen, 2011). Moreover, research in this field has the promise of theoretical advance on understanding transitional settings in terms of boundary crossing (Akkerman \& Bakker, 2011). Next, workplaces are technology-rich so studies of workplace mathematics advance our knowledge of the mediation of mathematics by technological tools (Hoyles et al., 2010). Ideas from the special issue may further generate more general interest because mathematics education in many countries is gradually shifting to more context-based instruction.

Studies in vocational settings further urge us to rethink some of the metaphors of learning commonly used in mathematics education. It is striking that acquisitionist and constructivist metaphors are not very popular in the vocational area (see the articles in this special issue and Wheelahan, 2009; Young, 2008). Far more popular are sociocultural and activity-theoretical perspectives with a focus on participation (cf. Sfard, 1998). However, as observed by Guile and Young (2003), the attention of activity-theoretical researchers on horizontal forms of development has long been at the expense of research into scientific concept development in practice (see also the Commentary by FitzSimons). Underpinning this observation, Derry (2013) noted a tendency among some sociocultural researchers to downplay the role of rationality that can be found in Vygotsky. One way to retain the sociocultural insights on the importance of activity and participation while maintaining the phenomenon of mathematical rationality is by focusing on webbing (see also Hahn's contribution on various kinds of rationality). Webbing refers to the meaning making involved in connecting situations, symbol systems, technological means and personal and professional knowledge (Noss \& Hoyles, 1996). The notion thus seems appropriate in settings where various kinds of knowledge, artefacts, procedures, norms, communities, purposes, et cetera, need to be connected to make sense of work processes. In line with the idea of webbing and sociocultural ideas, Bakker, Kent, Derry, Noss, and Hoyles (2008) and Bakker and Derry (2011) have used inferentialism to emphasise the rationality involved by focusing on what they term webs of reasonscomplexes of interconnected reasons, premises and conclusions, inferences, implications, motives for action and utility of tools for particular purposes in a particular context. An important goal of vocational education is thus to make students aware of rich webs of reasons at stake in work tasks. Illustrations of students' and apprentices' webbing, though in other terms, can be found in this issue.

\section{Structure of the special issue}

The special issue consists of two parts followed by a commentary paper. The first part aims to characterise vocational mathematical knowledge; the second part shows how such knowledge can be developed. However, the boundaries are not strict, and each article can be read independently from any other.

The first part starts with an article by Lionel LaCroix on the mathematical activity of preapprentices in the pipe industry. His research confirms many observations of others in terms of the technology-mediated nature of mathematical activity interwoven with contextual elements, but he presents a more positive image than has been reported in previous decades. For example, he reports that "preapprentice coursework was perceived as targeted towards their being able to work productively on the job."

Wolff-Michael Roth compares how electrician apprentices learn to bend electrical conduits in college and at work. Although there were sharp contrasts between the sites, he argues that apprentices found ways to account for the differences in their stories. He thus argues that, 
rather than focusing on boundaries, we should focus on personality and the process of what he calls subjectification.

David Swanson and Julian Williams also problematise the popular dichotomy of school and out-of-school mathematics and the tendency of sociocultural researchers to "glamorise" authentic and situated workplace mathematics. Using examples from dart playing and mathematics teaching, they propose a "unified view of mathematics, outside and inside school, on the basis of Vygotsky's approach to everyday and scientific thought".

The second part of the special issue includes intervention studies. Arthur Bakker, Djonie Groenveld, Monica Wijers, Sanne Akkerman and Koeno Gravemeijer report on an intervention with a computer tool designed to foster proportional reasoning involved in dilution. The computer tool hybridised mathematical and workplace tasks. Participants were first-year laboratory technician students. The results show that the computations involved in dilution could be learned efficiently and effectively.

Next, Arthur Bakker and Sanne Akkerman report on an intervention in the final year of laboratory education aimed to help students integrate various types of knowledge. Their boundary-crossing approach indeed seems promising in fostering reflection in the form of perspective taking and making, leading to more integrated statistical and workplace-related knowledge.

Corinne Hahn has taken a somewhat similar approach, although using a different theoretical orientation, with business school students in a master's programme. In her analysis, she focuses on the different forms of rationality (technical, pragmatic and scientific) they used in doing the learning activity.

In the context of nursing, Diana Coben and Keith Weeks address the question of how teaching, learning and assessment should be designed when workplace demands on safety are critical. They focus on medication dosage calculations. Their work emphasises how many reasons of a different nature (mathematical, medical, safety-related, regulatory, assessability, etc.) are at stake when aligning teaching, learning and assessment in a vocational setting.

Geoff Wake then asks a crucial but difficult question: What can we learn from research in this field for the design of mathematics curricula in general education? He draws attention to the importance of doing and becoming, in addition to the traditional focus on mathematics content. Moreover, he formulates five principles for curriculum design.

Finally, Gail FitzSimons comments on the articles. The breadth and depth of the articles in this special issue demonstrate that this small field has made progress since the major studies reported in the 1980s and 1990s (e.g., Bessot \& Ridgway, 2000; Lave, 1988; Nunes et al., 1993). In particular, researchers have increasingly come to think beyond dichotomies such as school versus work and have become interested in what happens at the boundaries. Researchers and educators have further developed ways to support students and apprentices in developing the mathematical knowledge required in particular vocations or professions. However, it is also clear that there is still a long way to go (Sträßer, 2014). Despite the economic importance of vocational education and workplace training, very little research is carried out in this area that yet has the potential to connect several bodies of literature in innovative and relevant ways. I would like to end with an invitation to researchers in whatever related discipline to study this interesting area. Whatever profession or focus you choose, it is very likely you can contribute both practically and theoretically to the fields of vocational education, workplace learning or mathematics education.

Acknowledgments This special issue was possible due to grants from PROO (411-06-205) of the Netherlands Organisation for Scientific Research (NWO) and Educational and Learning Sciences Utrecht. I also thank Sanne 
Akkerman for her contributions in initiating this special issue. As guest editors, Gail FitzSimons and I would like to express our appreciation of the generosity of time and critical insights from the reviewers.

Open Access This article is distributed under the terms of the Creative Commons Attribution License which permits any use, distribution, and reproduction in any medium, provided the original author(s) and the source are credited.

\section{References}

Akkerman, S. F., \& Bakker, A. (2011). Boundary crossing and boundary objects. Review of Educational Research, 81, 132-169.

Akkerman, S. F., \& Bakker, A. (2012). Crossing boundaries between school and work during apprenticeships. Vocations and Learning, 5(2), 153-173.

Bakker, A., \& Derry, J. (2011). Lessons from inferentialism for statistics education. Mathematical Thinking and Learning, 13, 5-26. doi:10.1080/10986065.2011.538293.

Bakker, A., Kent, P., Derry, J., Noss, R., \& Hoyles, C. (2008). Statistical inference at work: The case of statistical process control. Statistics Education Research Journal, 7(2), 130-145.

Bakker, A., Kent, P., Hoyles, C., \& Noss, R. (2011). Designing for communication at work: A case for technology-enhanced boundary objects. International Journal of Educational Research, 50(1), 26-32. doi: 10.1016/j.ijer.2011.04.006.

Bessot, A., \& Ridgway, J. (Eds.). (2000). Education for mathematics in the workplace. Dordrecht: Kluwer Academic Publishers.

Brown, J. S., Collins, A., \& Duguid, P. (1989). Situated cognition and the culture of learning. Educational Researcher, 18, 32-41.

Damlamian, A., Rodrigues, J. F., \& Sträßer, R. (Eds.). (2013). Educational interfaces between mathematics and industry: Report on an ICMI-ICIAM-study. New York: Springer.

Derry, J. (2013). Kygotsky: Philosophy and education. Chichester: Wiley Blackwell.

Dierdorp, A., Bakker, A., Eijkelhof, H. M. C., \& van Maanen, J. A. (2011). Authentic practices as contexts for learning to draw inferences beyond correlated data. Mathematical Thinking and Learning, 13, 132-151. doi: $10.1080 / 10986065.2011 .538294$.

FitzSimons, G. E. (2002). What counts as mathematics? Technologies of power in adult and vocational education. Dordrecht: Kluwer Academic Publishers.

Greeno, J. G. (1998). The situativity of knowing, learning, and research. American Psychologist, 53, $5-26$.

Guile, D., \& Young, M. (2003). Transfer and transition in vocational education: Some theoretical considerations. In T. Tuomi-Gröhn \& Y. Engeström (Eds.), Between school and work: New perspectives on transfer and boundary-crossing (pp. 19-38). Amsterdam: Pergamon.

Hahn, C. (2000). Teaching mathematics to apprentices: Exploring content and didactical situations. In A. Bessot \& J. Ridgeway (Eds.), Education for mathematics in the workplace (pp. 159-166). Dordrecht: Kluwer Academic Publishers.

Hoyles, C., Bakker, A., Kent, P., \& Noss, R. (2007). Attributing meanings to representations of data: The case of statistical process control. Mathematical Thinking and Learning, 9, 331-360.

Hoyles, C., Noss, R., Kent, P., \& Bakker, A. (2010). Improving mathematics at work: The need for technomathematical literacies. Abingdon: Routledge.

Hutchins, E. (1995). Cognition in the wild. Cambridge: MIT Press.

Lave, J. (1988). Cognition in practice: Mind, mathematics and culture in everyday life. Cambridge: Cambridge University Press.

Lave, J., \& Wenger, E. (1991). Situated learning: Legitimate peripheral participation. Cambridge: Cambridge University Press.

Noss, R., \& Hoyles, C. (1996). Windows on mathematical meanings: Learning cultures and computers. Dordrecht: Kluwer Academic Publishers.

Noss, R., Pozzi, S., \& Hoyles, C. (1999). Touching epistomologies: Meanings of average and variation in nursing practice. Educational Studies in Mathematics, 40, 25-51.

Nunes, T. A., Schliemann, D., \& Carraher, D. W. (1993). Street mathematics and school mathematics. Cambridge: Cambridge University Press.

Roth, W., \& Lee, Y. (2007). "Vygotsky's neglected legacy": Cultural-historical activity theory. Review of Educational Research, 77, 186-232. 
Sfard, A. (1998). On two metaphors for learning and the dangers of choosing just one. Educational Researcher, 27(2), 4-13.

Sträßer, R. (2014). History of teaching vocational mathematics. In A. Karp \& G. Schubring (Eds.), Handbook on the history of mathematics education (pp. 515-524). New York: Springer. doi:10.1007/978-1-4614-9155-2 25.

Tuomi-Gröhn, T., \& Engeström, Y. (2003). Conceptualizing transfer: From standard notions to developmental perspectives. In T. Tuomi-Gröhn \& Y. Engeström (Eds.), Between school and work: New perspectives on transfer and boundary-crossing (pp. 19-38). Amsterdam: Pergamon.

Wheelahan, L. (2009). The problem with CBT (and why constructivism makes things worse). Journal of Education and Work, 22, 227-242.

Williams, J. S., \& Wake, G. D. (2007). Black boxes in workplace mathematics. Educational Studies in Mathematics, 64(3), 317-343.

Young, M. (2008). Bringing knowledge back in: From social constructivism to social realism in the sociology of education. London: Routledge. 